\title{
Adverse Drug Reactions in Hospitalized-Geriatric Patients with Hypertension
}

\author{
Andi I. Julianti ${ }^{1}$, Lia Amalia ${ }^{2}$, Sri Hartini ${ }^{2}$ \\ ${ }^{1}$ Department of Pharmacology, Bumi Siliwangi Academy of Pharmacy, \\ Bandung, West Java, Indonesia \\ ${ }^{2}$ Department of Pharmacology and Toxicology, Bandung Institute of Technology, \\ Bandung, West Java, Indonesia
}

\begin{abstract}
Adverse drug reactions (ADRs) occur often in geriatric patients due to various factors which include a decrease in the physiological function and organs, nutritional deficiencies, multipathology, and polypharmacy. This study aimed to identify and analyse ADRs of hospitalized-geriatric patients with hypertension. We conducted a cross-sectional retrospective study (August 2012 to January 2013). Probability determination was calculated by the Naranjo scale. The subjects on this study were hospitalized-geriatric patients $(n=86,46.51 \%$ male, and $53.48 \%$ female). Thirty-one patients (11 men and 20 women) participated in this study by completing questionnaires to calculate ADRs probability using the Naranjo scale. The probability results were 7 probable, 8 possible, and 16 doubtful. Moreover, we observed that there were drug-related problems (DRP) during therapy, e.g., appropriate dose $(59.37 \%)$, and inappropriate dose $34.37 \%$. It can be concluded that in hospitalized-geriatric patients with hypertension, some problems related to ADRs remain existed.
\end{abstract}

Keywords: geriatric, hypertension, adverse drug reactions

\section{Introduction}

World Health Organisation (WHO) describes ADRs as a response to a drug which is noxious and unintended and occurs at normal doses for prophylaxis, therapy, and for the modification of physiologic function. ${ }^{1}$ ADRs affect the patients' quality of life and may cause morbidity and mortality. ${ }^{2}$ The prevalence of ADRSs increase with age, especially in hospitalized-geriatric patients. ${ }^{3-5}$

ADRs should be defined, recorded, and identified in order to minimize the risk. ${ }^{6}$
Geriatric patients mostly suffer from comorbid diseases, electrolyte and fluid imbalance, which leads to polypharmacy as a major factor in triggering side effects. ${ }^{7}$

There are currently 600 million people suffer from hypertension and more than two-thirds of them are above aged $65 .{ }^{8}$ It is estimated that in 2025 , the number will increase by $80 \%{ }^{9}{ }^{9}$ Regarding to the high prevalence of ADRs in patients with hypertension, we examined ADRs in hypertension patients, including the identification, analysis, and evaluation

Corresponding author: Andi I. Julianti, Department of Pharmacology, Bumi Siliwangi Academy of Pharmacy, Bandung, West Java, Indonesia. Email: julianti3gh@gmail.com

Received: 15 October 2019. Revised: 29 November 2019. Published: 6 December 2019. 
in a hospital in Bandung that has special geriatric treatment facilities, by correlating the disease complications (multipathology) and polypharmacy.

\section{Methods}

This research was conducted at a hospital in Bandung. This study used cross-sectional retrospective methods (August 2012 to January 2013) to identify, analyse, and evaluate ADRs in geriatric patients with hypertension.

Inclusion criteria were patients:

1. Agedmorethan 65 years with hypertension from August 2012 to January 2013

2. Received antihypertensive drugs

3. Complete medical record (demographic data, diagnosis, previous disease history, drug history, the examination of vital signs, drug use, and laboratory examination data)

Exclusion criteria were patients:

1. Disagree to participate in the further

2. Patients who failed to cooperate during the period of study

The results were shown in tabular form and analysed quantitatively using the Naranjo scale.

\section{Results and Discussion}

A total population of 283 patients with hypertension were identified during the study period. Of these, 86 patients $(46.51 \%$ male and $53.48 \%$ female) were the targeted population. Based on retrospective data sampling of inpatient hypertension patients from August 2012 to January 2013, the main diagnostic data obtained is provided in Table 1.

The most additional diagnoses were: hypertension grade $2(26.74 \%)$, coronary heart disease $(33.72 \%)$, hypertension with heart failure $(26.74 \%)$, and diabetes mellitus $(23.26 \%)$.

In this study, the monitoring of therapy was done by collecting objective data from laboratory results, physical examination, and vital signs examination. Vital signs examinations were routinely measured by nurses, including blood pressure, pulse frequency, body temperature, respiration rate, and routine laboratory examination data. Based on the data, problems related to medicine could be analysed. Problems related to drug use in this study were:

1. Failed to receive treatment

2. Appropriate dose

3. Inappropriate dose

4. Drug interactions.

We used 31 medical data that supported from demographic data, laboratory data, and drug use data.

ADRs are major cause of morbidity, and mortality. Thus, it is essential to recognize ADRs to identify a relationship between the

Table 1. Overview of the Number of Patients with Hypertension as The Primary Diagnosis

\begin{tabular}{clcc}
\hline ICD Code & Primary Diagnose & Sigma & $\mathbf{\%}$ \\
\hline I 10 & Primary hypertension & 45 & 52.23 \\
I 11 & Hypertension with congestive heart failure & 25 & 29.07 \\
I 13.2 & Hypertension with kidney failure and congestive heart failure & 7 & 8.14 \\
I 13.9 & Hypertension with kidney disease and unspecific heart disease & 4 & 4.65 \\
I 12.0 & Hypertension with kidney failure & 3 & 3.48 \\
1 II.9 & Hypertension without congestive heart failure & 2 & 2.33 \\
& & 86 & 100.00 \\
\hline
\end{tabular}


Table 2. Drug Related Problems during Hospitalization

\begin{tabular}{lcccc}
\hline \multirow{2}{*}{ Drug Related Problem } & \multicolumn{2}{c}{ Gender } & Total Number & \multirow{2}{*}{ of Patients } \\
\cline { 2 - 4 } & Female & Male & 19 & 59.37 \\
\hline Appropriate dose & 7 & 12 & 11 & 34.37 \\
Inappropriate dose & 2 & 9 & 30 & 93.75 \\
Patient with drug-related problem & 9 & 21 & & \\
\hline
\end{tabular}

drug and the adverse effect. Many causality methods have been published, but none is specifically used in older patients with multiple comorbidities and polypharmacy. WHO-Uppsala Monitoring Center criteria and the Naranjo criteria are frequently cited in the medical literature. ${ }^{10-13}$

Probability score as "possible" categorized when It is followed a temporal sequence after a drug, possibly followed a recognized pattern to the suspected drug, and it could be explained by characteristics of the patient's disease. This problem can be treated by stopping or replacing the drug (de-challenge). "Probable" categorized when it is followed a reasonable temporal sequence after a drug, a recognized response to the suspected drug, confirmed by withdrawal but not by exposure to the drug, and it could not be reasonably explained by the known characteristics of the patient's clinical state. Re-challenge is not required. "Doubtful" categorized when the response cannot be identified whether due to the drug use or patient's disease. ${ }^{14}$

This data showed the probability score that can help us to identify DRP. We can assess the goal of therapy and decrease the possibility of the side effect and new DRP. Moreover, we can arrange plans to solve the problem by listing the avoided drugs and monitoring parameters (both therapeutic and toxicity). Most importantly, we need to explain that information and educate patients to prevent ADRs.

In summary, there were 86 hospitalized geriatric patients with hypertension. 31 patients ( 10 men and 21 women) were chosen to take "Probability Score" assessment. The results showed the ADRs patient's status were 7 probable, 8 possible, and 16 doubtful. There were $59.37 \%$ of appropriate dose, and $34.37 \%$ of inappropriate dose. Moreover, we also found 47 severe interactions and 6 major interactions. Treatment recommendations that need to be done to prevent the occurrence of ADRs is to assess the dose of administration by considering the drugs that has been used, then the risk factors from the patient.

\section{Conclusion}

ADRs are common clinical problem in geriatric and contribute significantly to morbidity and mortality. As medication

Table 3. Probability Scales for Quantitative Adverse Drug Reactions Using Naranjo Scale

\begin{tabular}{|c|c|c|}
\hline Probability Score & Score & Number of Patient \\
\hline Definite & $>9$ & - \\
\hline Probable & $5-8$ & 7 \\
\hline Possible & $1-4$ & 8 \\
\hline \multirow[t]{2}{*}{ Doubtful } & $<0$ & 16 \\
\hline & Total Number of Patients & 31 \\
\hline
\end{tabular}


experts, pharmacists play a role in management of ADRs. Probability score that was found will help us to identify DRP. Furthermore, additional steps should be taken to determine the cause of the patient's symptoms and whether they can be attributed to the use of a drug.

\section{Acknowledgements}

We thank all staff and lecturers in the Department of Pharmacology, Bumi Siliwangi Academy of Pharmacy, and the Department of Pharmacology and Toxicology, Bandung Institute of Technology for technical assistance and advice.

\section{Funding}

None.

\section{Conflict of Interest}

None declared.

\section{References}

1. World Health Organization (WHO). WHO Draft Guidelines for Adverse Event Reporting and Learning Systems. Geneva: WHO, 2005.

2. Schatz SN, Weber RJ. Adverse Drug Reactions (Adverse Drug Effects). Pharmacother Self-Assessment Program. 2015;42(1):12-16.

3. Beijer HJM, De Blaey CJ.Hospitalisations caused by adverse drug reactions (ADRs): A meta-analysis of observational studies. Pharmacy World and Science. 2002;24(2):46-54.

4. Pirmohamed M, James S, Meakin S, Green C. Adverse drug reactions as cause of admission to hospital: Authors' reply. Bmj. 2004;329(7463):460.

5. Kongkaew C, Noyce PR, Aschcroft DM. Annals of Pharmacotherapy Objective, Findings, Discussion, Conclusions. Annalysis of Pharmacotherapy. 2008;42(7):1017-1025.
6. Lavan AH, Gallagher P. Predicting risk of adverse drug reactions in older adults. Theapeutic Advance in Drug Safety. 2016;7(1):11-22.

7. Brooks JO, Hoblyn JC. Secundary mania in older adults. American Journal of Psychiatry. 2005;162:2033-8.

8. Chobanian AV, Bakris GL, Black HR, Cushman WC, Green LA, Izzo JL, Jones DW, Materson BJ, Oparil S, Wright JT, Roccella EJ. The Seventh Report of the Joint National Committee on Prevention, Detection, Evaluation, and Treatment of High Blood Pressure: the JNC 7 report. Journal of American Medical Association. 2003;289:2560-2572.

9. Nawi R, Arsunan A, Jalla K. Analisis Faktor Risiko Kejadian Hipertensi pada Dewasa Muda di Unit Rawat Jalan Rumah Sakit Umum Labuang Baji Makasar. Jurnal Media Kesehatan Masyarakat Indonesia. 2006.

10. Levy D, Larson MG, Vasan RS, Kannel WB, Ho KK. The progression from hypertension to congestive heart failure. Journal of American Medical Association. 1996;275:1557-1562.

11. Danan G, Benichou C. Causality assessment of adverse reactions to drugs - I. A novel method based on the conclusions of international consensus meetings: application to drug-induced liver injuries. Journal of Clinical Epidemiology. 1993;46:1323-1330.

12. Maria V and Victorino, R. Development and validation of a clinical scale for the diagnosis of druginduced hepatitis. Hepatology. 1997;26:664-669.

13. World Health Organization. The use of the WHO-UMC system for standardized case causality assessment. World Health Organization, Uppsala Monitoring Centre. 2015.

14. Naranjo C, Busto U, Sellers E, Sandor P, Ruiz I, Roberts E. A method for 
estimating the probability of adverse drug reactions. Clinical Pharmacology Therapy. 1981;30:239-245. 